\title{
Ethics of Publishing Case Reports: Do We Need Ethics Approval and Patient Consent?
}

\author{
Mehrdad Jalalian
}

Editor-in-Chief, Electronic Physician Journal, Mashhad, Iran

Type of article: Editorial

\begin{abstract}
This brief editorial proposes a novel approach to optimizing the editorial procedures for submitting of institutional review board approval and consent forms to journals.

Keywords: Case Report, Publication Ethics, Consent Form, Ethical Approval
\end{abstract}

\section{Editorial:}

For nearly three decades, the ethics of publishing case reports has been a source of contention $(1,2)$. The central point of the debate has been the requirement to submit a consent form signed by the patient or a proxy (1-4). Even if the case reports are not considered full scale retrospective studies, the second element of ethics of publication report has been the ethical approval or the approval letter signed by the institutional review board. However, providing the journal with written informed consent appears to be ethically appealing. Furthermore, when a patient enters a hospital or clinic, they read and sign a form allowing the institute to use their data anonymously for the advancement of medical science. My recommendation is that any approval letter from the institute/hospital stating that the institutional review board has approved the case reporting and they have received a general signed form from the patient on the date of attendance is sufficient for publishers to ascertain the ethics of publishing case reports.

\section{Conflict of Interest:}

There is no conflict of interest to be declared.

\section{References:}

1) Barbour V on behalf of COPE Council. Journals' Best Practices for ensuring consent for publishing medical case reports: guidance from COPE. December 2016. doi: 10.24318/cope.2019.1.6

2) J Vollmann. ["Informed consent" by the patient for publication of case reports. New guidelines by the "International Committee of Medical Journal Editors" (Vancouver Group)]. Nervenarzt. 1996 May;67(5):422-6. PMID: 9005356

3) Mark Neavyn, Christine Murphy. Coming to a Consensus on Informed Consent for Case Reports. J Med Toxicol. 2014 Dec; 10(4): 337-9. doi: 10.1007/s13181-014-0421-4. PMCID: PMC4252295, PMID: 25135309

4) Stephen B. Levine, Susan J. Stagno. Informed Consent for Case Reports: The Ethical Dilemma of Right to Privacy Versus Pedagogical Freedom. J Psychother Pract Res. 2001 Summer; 10(3): 193-201. PMCID: PMC3330645, PMID: 11402083

\section{Corresponding author:}

Dr. Mehrdad Jalalian. Editor-in-Chief, Electronic Physician Journal, Mashhad, Iran.

Tel: +98.9164337176, E-mail: mehrdad.medic@gmail.com

Received: December 12, 2020, Accepted: April 08, 2021, Published: June 2021

(C) 2021 The Authors. This is an open access article under the terms of the Creative Commons Attribution-NonCommercialNoDerivs License, which permits use and distribution in any medium, provided the original work is properly cited, the use is non-commercial and no modifications or adaptations are made. 